Wir wünschen Ihnen recht viel Vergnügen bei der Lektüre dieses Themenheftes!

Helmut Malleck

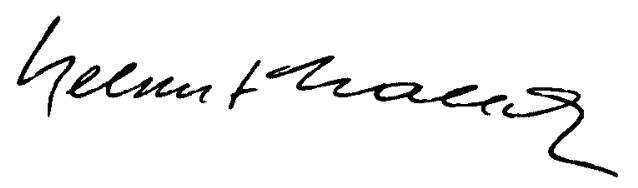

Alfred Veider

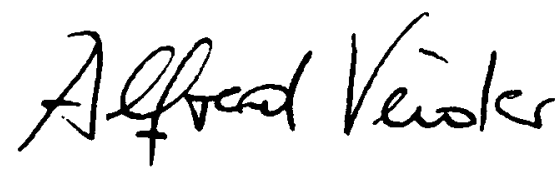

\title{
Innovationspotenzial im Eisenbahnwesen Österreichs
}

Europas bisher weitgehend nationale Eisenbahnen unterliegen seit geraumer Zeit einem der umfassendsten Veränderungsprozesse seit ihrem Bestehen. Die von der EU beabsichtigten Maßnahmen im Eisenbahnwesen, die durch verschiedene Richtlinien und die Pakete 2004 und 2006 definiert sind, erzwingen umfangreiche Reformen und das Einstellen auf einen nummehr ebenfalls liberalisierten Schienenverkehrsmarkt, auf dem in der Folge neue und unabhängige Eisenbahnverkehrsunternehmen (EVUs) erscheinen.

Damit soll schließlich erreicht werden, dass die Bahnen in der EU zu kräftigen Mitbewerbern zur Straße auf dem Verkehrsmarkt auftreten können. Dies zwingt $z u$ intensivem Handeln, das Änderungen im inhaltlichen, strategischen und damit auch im technologischen Bereich erfordert. führt:

Zur Verdeutlichung seien nur einige der EU-Vorgaben ange-

- Trennung von Absatz (Personen- und Güterverkehr) und Infrastruktur mit Verbot der Querfinanzierung,

- Liberalisierung des Netzzugangs (Förderung des Wettbewerbs),

- einheitliche technische Vorschriften für Hochgeschwindigkeitsverkehr und konventionelle Verkehre (Schaffung europaweit einheitlicher Systemmodule und technischer Parameter),

- und letztlich die Version eines einheitlichen Eisenbahnsystems für Europa in der Gruppierung „European Rail Research Advisory Council“" (ERRAC).

Vorstehende Gegebenheiten sind für die Eisenbahnverkehrsunternehmen, die einschlägige Industrie und nicht zuletzt auch für die wissenschaftlichen Institutionen eine große Herausforderung. Für den Standort Österreich und das in diesem Lande erworbene Know-how ist es unabdingbar, F \& E-Aktivitäten zu bündeln, um auch in Zukunft den derzeit noch gehaltenen Vorsprung der österreichischen Eisenbahnindustrie abzusichern, weiter auszubauen und damit auch breiter zu verankern.

Diesem Ziel dienen Aufbau und Etablierung des Ende 2003 gegründeten „Rail Technology Cluster Austria“ (RTCA), in dem sich Bahn-affine Industrie von Großunternehmen bis hin zu Klein- und Mittelbetrieben (KMUs), wissenschaftliche Institutio- nen und Eisenbahnverkehrsunternehmen zur Entwicklung und Förderung innovativer Maßnahmen zusammengeschlossen haben.

Die Standortsicherung für seine Mitglieder ist $\mathrm{zu}$ unterstützen, wobei eine wirtschaftliche Vorreiterrolle in Europa anzustreben ist, d. h. eine unangefochtene Rolle der heimischen Lokationen im internationalen Wettstreit zwischen Unternehmen und innerhalb der Konzerne zu erreichen.

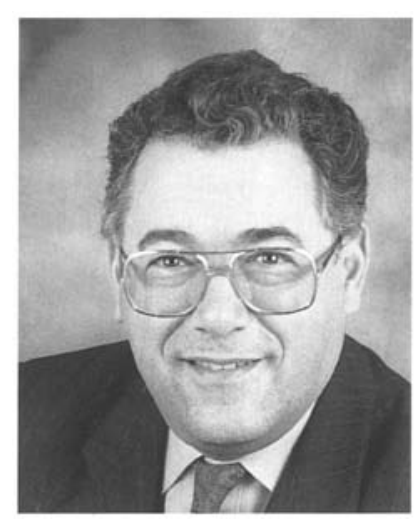

Dipl.-Ing. Helmut Hainitz
Im ersten grundlegenden Schritt war es erforderlich, die eigenen Stärken zu kennen, um sich in den vom "European Rail Research Advisory Council" (ERRAC) genannten fünf strategischen Forschungsprioritäten („Strategic Rail Research Agenda“ - SRRA) entsprechend einbringen zu können. Diese fünf Forschungsprioritäten sind:

- Interoperabilität

- Intelligente Mobilität

- Sicherheit

- Umwelt

- Innovative Werkstoff- und Produktionsmethoden

Möge die vorliegende Publikation als Bestätigung für das vorhandene Innovationspotenzial und als Anregung dienen.

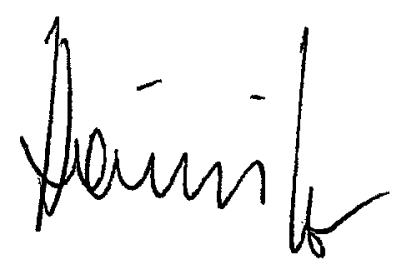

Gen.-Dir.-Stv. i. R. Dipl.-Ing. Helmut Hainitz

Präsident des RTCA - Rail Technology Cluster Austria 